\title{
Article
}

\section{Biphasic effects of perfluorooctanoic acid on steroidogenesis in mouse Leydig tumour cells}

Tian, Meiping, Huang, Qingyu, Wang, Heng, Martin, Francis L, Liu, Liangpo, Zhang, Jie and Shen, Heqing

Available at http://clok.uclan.ac.uk/25522/

Tian, Meiping, Huang, Qingyu, Wang, Heng, Martin, Francis L ORCID: 00000001-8562-4944, Liu, Liangpo, Zhang, Jie and Shen, Heqing (2019) Biphasic effects of perfluorooctanoic acid on steroidogenesis in mouse Leydig tumour cells. Reproductive Toxicology, 83 . pp. 54-62. ISSN 0890-6238

It is advisable to refer to the publisher's version if you intend to cite from the work. http://dx.doi.org/10.1016/j.reprotox.2018.11.006

For more information about UCLan's research in this area go to http://www.uclan.ac.uk/researchgroups/ and search for <name of research Group>.

For information about Research generally at UCLan please go to http://www.uclan.ac.uk/research/

All outputs in CLoK are protected by Intellectual Property Rights law, including Copyright law. Copyright, IPR and Moral Rights for the works on this site are retained by the individual authors and/or other copyright owners. Terms and conditions for use of this material are defined in the policies page.

\section{CLoK}

Central Lancashire online Knowledge www.clok.uclan.ac.uk

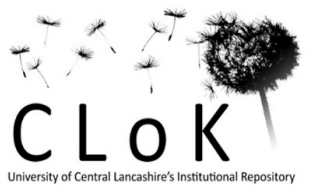


3 Meiping Tian ${ }^{\mathrm{a}, \mathrm{b}}$, Qingyu Huang ${ }^{\mathrm{a}}$, Heng Wang ${ }^{\mathrm{a}}$, Francis L Martin ${ }^{\mathrm{c}}$, Liangpo Liu ${ }^{\mathrm{a}}, \mathrm{Jie}$ Zhang $^{\mathrm{a}}$, 4 Heqing Shen ${ }^{\mathrm{a}^{*}}$

${ }^{\mathrm{b}}$ University of Chinese Academy of Science, Beijing 100049, China;

\section{Leydig tumour cells}

${ }^{a}$ Key Laboratory of Urban Environment and Health, Institute of Urban Environment, Chinese Academy of Sciences, Xiamen 361021, China;

'School of Pharmacy and Biomedical Sciences, University of Central Lancashire, Preston PRI 2HE, UK

${ }^{1}$ To whom correspondence may be addressed: Prof. Heqing Shen, Institute of Urban Environment, Chinese Academy of Sciences, 1799 Jimei Road, Xiamen 361021, China; Telephone/Fax: (86)-592-6190771; E-mail: hqshen@iue.ac.cn 
Perfluorooctanoic acid (PFOA) is a persistent organic pollutant, which may possess endocrine disrupting properties. Herein, we investigated the possible mechanism(s) of toxicity and steroidogenesis in mouse Leydig cells. MLTC-1 (mouse Leydig tumour cells) cells were exposed to $0,50,100$ or $200 \mu \mathrm{M}$ PFOA for $48 \mathrm{~h}$ to ascertain their effects on the nuclear (membrane) receptor responses, steroidogenesis pathway and related regulated gene expression and steroid hormone secretion profiles. Our results reveal that nuclear receptor $P X R, S R-B 1$ and $L H R$ are sensitive to PFOA exposure. PFOA can accumulate in mitochondria and alter cholesterol precursor (fatty acid) mitochondrial transport process-related gene expression and thus inhibit steroid hormone precursor (cholesterol) production. In particular, PFOA exhibits biphasic effects on testosterone and progesterone production at differing levels of exposure. These findings indicate the potential endocrine-related effects of PFOA on steroid hormone secretion in Leydig cells and point to a novel disruption model.

Key Words: Perfluorooctanoic acid; endocrine disruption; biphasic effects; MLTC-1 cells; steroidogenesis; steroid hormone 


\section{Introduction}

Perfluorinated compounds (PFCs) are a group of synthetic chemical substances consisting of carbon-fluorine bonds, and well known for their uses in a wide range of industrial applications due to their unique properties of stability, lipophobicity and hydrophobicity. In recent years, widespread distribution of PFCs into different environmental matrices has become an important concern due to their bioaccumulation in different tissues of humans and wildlife [1]. Given its longer half-life, perfluorooctanoic acid (PFOA) is one of the most widely reported PFCs in exposed biological species [1]. The general population has both PFOA and perfluorooctanesulfonic acid (PFOS) typically present at blood concentrations ranging from approximately 10-100 $\mathrm{nM}[2,3]$. However, levels of PFOA in serum of occupationally-exposed workers can be $10 \mu \mathrm{M}$ or higher $[2,4]$.

Recently, it has been suggested that PFOA might cause several health effects in animals and humans, including reproductive impairments, neurological disorders, liver toxicity and development abnormalities [5-7]. An in vivo animal toxicity study has shown that PFOA has the ability to cause several types of tumours, including in Leydig cells [8]. In particular, PFOA has been considered a potential endocrine disrupting chemical, causing male reproductive system-related abnormalities. Taking this into consideration, many studies have reported that PFOA may interrupt sex hormone functions either by decreasing serum testosterone $(\mathrm{T})$ levels and/or increasing serum oestradiol $\left(\mathrm{E}_{2}\right)$ levels in rodents $[9,10]$ and increasing serum testosterone and oestrone levels in fish species [11], disruption of gonad development in male fish [12], and altered human and rat steroidogenic enzyme activities [9, 10, 13]. That said, human epidemiology studies into the relationship between PFOA 
concentrations and hormone levels in humans have been inconsistent. Some studies suggest a negative association of PFOA levels with serum total testosterone and free testosterone, and a positive association with oestradiol [14-16]. In contrast, a positive relationship between total testosterone with concentrations of PFOA have also been reported [17], while no such associations were found in human epidemiology or in vitro toxicology studies $[18,19]$. Similarly, a similarly ambiguous association of PFOA levels and semen quality has also been documented. For example, lower sperm concentrations and total sperm count per ejaculate were associated with in utero PFOA exposure levels [20]. High levels of PFOA were also associated with reduced numbers of normal human sperm [21]. Contrary to this, some studies suggest that there is no correlation between PFOA and human semen quality, including sperm concentration, count, volume, motility and morphology [21, 22].

Studies investigating the impact of PFOA on male reproductive health are controversial. Further studies will need to be undertaken to clarify the biological mechanisms underlying PFOA endocrine disruption. Testicular Leydig cells are the primary source of steroid hormone in the male. Steroid hormone production starts with cholesterol, which is converted into an intermediate prior to generation of the end product sex hormone, testosterone [23]. Mouse Leydig tumour cells (MLTC-1) are a useful model to study effects on steroidogenesis because of their steroidogenesis potency. In vivo and in vitro experiments also suggest that mouse Leydig cells appear to be more similar to human Leydig cells in their responses to environmental exposure than are those of the rat [24]. Consequently, mouse Leydig MLTC-1 cells were selected for the in vitro model towards assessment of PFOA endocrine disruption. The aim of this study is to improve our understanding of PFOA-induced endocrine 
disruption via molecular initiating events (receptor response) and endpoints (steroid hormone secretion) related to reproductive toxicity, by using mouse in vitro Leydig MLTC-1 cells.

\section{Materials and methods}

\subsection{Chemicals and reagents}

PFOA $\left(\mathrm{C}_{8} \mathrm{~F}_{15} \mathrm{O}_{2} \mathrm{H}\right.$; Chemical Abstract Service, no. 335-67-1; purity >96\%) and isotope PFOA ${ }^{13} \mathrm{C}_{8}$ was purchased from Cambridge Isotope Laboratories (Andover, MA, USA). Dimethyl sulfoxide (DMSO) was purchased from Sigma-Aldrich Chemical Co. (St. Louis, Mo. USA). Human chorionic gonadotrophin (hCG) was obtained from PROSPECT (Ness-Ziona, Israel). The steroid hormone standards of testosterone and 17-OH progesterone were purchased from Dr. Ehrenstorfer GmbH (Germany) and the isotope D3-testosterone was purchased from Cerilliant (Promochem, Wesel, Germany). All other chemicals of appropriate grades were commercially available.

\subsection{Cell culture and cell viability assay.}

The MLTC-1 cell line was obtained from the Cell Institute of Shanghai (Shanghai, China) and cultured in RPMI-1640 medium (Gibco BRL, Grand Island, NY) supplemented with $100 \mathrm{unit} / \mathrm{mL}$ penicillin, $100 \mathrm{unit} / \mathrm{mL}$ streptomycin and $10 \%(\mathrm{v} / \mathrm{v})$ foetal bovine serum (Hyclone, USA). The cells were grown at $37^{\circ} \mathrm{C}$ with $5 \% \mathrm{CO}_{2}$ in a humidified incubator (SANYO, Japan).

Cell viability was evaluated by the MTT proliferation assay. Cells were plated at a density of $1.5 \times 10^{4}$ per well in 96 -well plates. After 48 -h incubation at different concentrations of PFOA $(0-300 \mu \mathrm{M}), 50 \mu \mathrm{L}$ MTT $(5 \mathrm{mg} / \mathrm{mL})$ was added to each well and the 
cells were incubated for $4 \mathrm{~h}$ at $37^{\circ} \mathrm{C}$. Untreated cells were used as a negative control. The medium was removed and $150 \mu \mathrm{L}$ DMSO was added to each well and gentle shaking was then performed for $10 \mathrm{~min}$. Absorbance was determined at $490 \mathrm{~nm}$. Four replicates for each PFOA exposure were performed. Results were presented as percentage of the values measured in untreated control cells. To ensure absence of cytotoxicity, the concentrations 50 $\mu \mathrm{M}, 100 \mu \mathrm{M}$, and $200 \mu \mathrm{M}$ were selected for the following PFOA exposure experiments.

\subsection{PFOA treatment}

MLTC-1 cells were seeded in 6-cm petri dishes and cultured for $24 \mathrm{~h}$ prior to treatment. PFOA was dissolved in DMSO. Cells were exposed to $50 \mu \mathrm{M}, 100 \mu \mathrm{M}$ or $200 \mu \mathrm{M}$ PFOA for $48 \mathrm{~h}$, with DMSO (0.1\%) alone employed as a vehicle control. Four replicates for each dose of PFOA exposure were performed. Then, the cells were washed with PBS and serum-free medium. Subsequently, cells were stimulated for $4 \mathrm{~h}$ with $\mathrm{hCG}$ in serum-free medium supplemented by $0.1 \% \mathrm{BSA}$. The medium was collected for progesterone and testosterone determination, and the cells for cholesterol measurements and other biochemical assays.

\subsection{RNA extraction and quantitative real-time $R T P C R$ analysis}

To determine mRNA expression levels, a quantitative real-time RT PCR assay was performed. Total RNA was extracted from the cells using an RNA extraction kit (Promega, USA), following the manufacturer's protocol. Extracted RNA samples were stored at $-80^{\circ} \mathrm{C}$, for subsequent analyses. The NanoDrop spectrophotometer (NanoDrop Technologies Inc., USA) was used to measure RNA and/or DNA concentration and purity. Reverse transcription of cDNA synthesis was performed with $1 \mu \mathrm{g}$ total RNA using PrimeScript ${ }^{\circledR}$ RT reagent Kit with gDNA Eraser cDNA synthesis Kits (Takara, Japan) 
employing oligo dT primer. Real-time PCR was carried out in a $20 \mu \mathrm{L}$ final volume and performed in triplicate using SYBR Green Master Mix reagents (Roche, USA) in a $L C 480$ system (Roche Applied Science, Germany), according to the manufacturer's protocol. Primer sets and product sizes used for amplification PCR analysis are shown as Table 1. The conditions for quantitative PCR were as follows: $95^{\circ} \mathrm{C}$ for 10 min followed by 40 cycles at $95^{\circ} \mathrm{C}$ for $15 \mathrm{~s}$, and $60^{\circ} \mathrm{C}$ for $30 \mathrm{~s}$. Gene expression levels were normalized to $G A P D H$ expression levels. Three replicates of quantitative PCR were performed for each sample. Four replicates for each dose of PFOA exposure were performed. The fold changes of the tested genes were determined by the $2^{-{ }_{\mu} \mathrm{Ct}}$ algorithm approach.

\subsection{Cholesterol, progesterone and testosterone determination}

Total cholesterol (TCHO) content in MLTC-1 cells in the control and PFOA groups were measured using commercial kits according to the manufacturer's instructions (Beihua Kangtai Clinical Reagent, China). Total cholesterol concentration was normalized to Leydig cell protein concentration. Steroid hormones testosterone and progesterone levels in cell culture medium were detected by LC-ESI-MS/MS. In brief, each sample of $1 \mathrm{~mL}$ medium was diluted with $3 \mathrm{~mL}$ of ammonium acetate buffer $(1 \mathrm{~mol} / \mathrm{L})$, and $20 \mu \mathrm{L}$ of $100 \mathrm{ng} / \mathrm{mL}$ D3-testosterone internal standard was added (progesterone was semi-quantified). Then the diluted samples were extracted by adding $3 \mathrm{~mL}$ ethyl acetate and vortexed vigorously for 15 seconds in a glass tube. The liquid-liquid extraction was repeated three times. The following phase separation was completed by centrifugation at $1500 \mathrm{rpm}$ for $10 \mathrm{~min}$. The ether phase was transferred to another glass tube with a Pasteur pipette. The three times extract was combined and washed with $5 \mathrm{~mL}$ water, then the combined extracts were evaporated under a 
gentle stream of nitrogen gas at $40^{\circ} \mathrm{C}$. The residue was reconstituted with $200 \mu \mathrm{L}$ methanol/water (50:50, v:v) by vortexing vigorously for $15 \mathrm{sec}$ and transfer into a HPLC vial. The sample was stored at $-20^{\circ} \mathrm{C}$ until LC-MS-MS analysis. Two quality control samples and two sets of standards were analysed together with unknown samples in each analytical batch.

\subsection{Quantification of PFOA in cytoplasmic and mitochondrial fractions}

Mitochondrial isolation was performed using the Cell Mitochondria Isolation Kit

(Beyotime Institute of Biotechnology, China) according to the manufacturer's instructions.

Briefly, MLTC-1 cells were pelleted, washed, and re-suspended in ice-cold mitochondria isolation buffer. The cells were homogenized and centrifuged at $600 \mathrm{~g}$ for $10 \mathrm{~min}$ at $4^{\circ} \mathrm{C}$. The supernatant was centrifuged at $11,000 \mathrm{~g}$ for $10 \mathrm{~min}$ at $4^{\circ} \mathrm{C}$ to obtain mitochondrial pellets.

Mitochondrial-free cytoplasm was obtained from the supernatant. Mitochondrial pellets were lysed in a lysis buffer.

Mitochondrial lysate and cytoplasm were extracted by ion-pair extraction and solid-phase extraction (SPE) with subsequent HPLC-MS/MS quantification method, as previously outlined $[25,26]$. In brief, $0.03 \mathrm{ml}$ of mitochondrial lysate was made up to $1 \mathrm{~mL}$ with distilled water in a $15 \mathrm{~mL}$ PP tube (containing $10 \mathrm{ng} \mathrm{C}_{13} \mathrm{PFOA}$ internal standard). Before extraction, the spiked samples were allowed to equilibrate overnight at room temperature $\left(26^{\circ} \mathrm{C}\right)$. Then, $1 \mathrm{~mL}$ tetra- $n$-butylammoniumhydrogen sulfate and $2 \mathrm{~mL}$ sodium carbonate (0.25 M, pH 10) were added. After mixing, $5 \mathrm{~mL}$ MTBE was added, and the mixture was shaken for $15 \mathrm{~min}$ at $250 \mathrm{rpm}$. The organic and the aqueous layers were separated by centrifugation at $3000 \mathrm{rpm}$ for $15 \mathrm{~min}$. Then, $4 \mathrm{~mL}$ MTBE supernatant was removed and transferred to another $15 \mathrm{~mL}$ PP tube. This procedure was twice repeated, except that $5 \mathrm{~mL}$ 
MTBE was collected each time. All three extracts were combined, and evaporated to dryness under a gentle stream of nitrogen at $45^{\circ} \mathrm{C}$. Finally the dried residue was re-suspended in 0.5 $\mathrm{mL}$ of methanol/water (50:50, v:v) before analysis. Calibration standards and QC samples were analysed concurrently with unknown samples using the same sample preparation procedure.

\subsection{Statistical analysis}

Measurement data of cholesterol, progesterone, testosterone levels and gene expression by real-time RT PCR analysis were analysed using SPSS for Windows 11.5 Software (SPSS, Inc., Chicago, IL) and were presented as mean with standard errors (mean \pm SE). The experiments were repeated four times, each in duplicate. Data were analysed by one-way ANOVA with Tukey's multiple comparisons test. Asterisks above columns indicate a significant difference in comparison to the control, ${ }^{*} p \leq 0.05, \stackrel{* *}{p} \leq 0.01$.

\section{Results}

\subsection{Cell viability assay}

To analyse the effects of PFOA on MLTC-1 cell viability, the cells were treated with different doses (from 0 to $300 \mu \mathrm{M}$ ) of PFOA for $48 \mathrm{~h}$. Results of cytotoxicity studies are shown in Figure 1. Taking into account effects on cell viability, the PFOA concentrations were kept below the levels (i.e., $300 \mu \mathrm{M}$ ) at which significant lethal effects occurred. Exposure concentrations in subsequent experiments were as follows: 0, 50, 100 or $200 \mu \mathrm{M}$.

\subsection{Nuclear (membrane) receptor responses to PFOA exposure}

As nuclear (membrane) receptor is involved in environmental exposure and 
toxicological effects, transcript profiles of nuclear (membrane) receptor were investigated in MLTC-1 cells exposed to varying levels of PFOA. The mRNA expression of PPAR $\alpha$ (PPAR-alpha; controls the peroxisomal $\beta$-oxidation pathway of fatty acids) was unaltered following PFOA exposure compared to control (Fig. 2). $A R$ (androgen receptor; is activated by binding androgenic hormones and then regulates male sexual phenotype gene expression) gene exhibits significantly reduced expression following 50 or $100 \mu \mathrm{M}$ PFOA, while no significant alteration is observed at the higher dose (i.e., $200 \mu \mathrm{M}$ ) PFOA treatment. PXR (Pregnane X receptor; regulates a broad range of genes involved in the transport, metabolism and elimination of foreign toxic substances) gene was significantly up-regulated in a dose-related fashion after PFOA exposure $(p<0.05)$ (Fig. 2). There was no significant alteration found at lower levels of PFOA (i.e., $50 \mu \mathrm{M}$ ) on LHR (luteinizing hormone receptor; allows Leydig cells to respond to luteinizing hormone that triggers these cells to produce androgens) gene expression. However, $100 \mu \mathrm{M}$ PFOA significantly induced $(p<0.05) L H R$ expression (Fig. 2). However, significant down-regulation $(p<0.01)$ was observed following $200 \mu \mathrm{M}$ PFOA exposure. Considering Figure 2, it can be identified that $S R-B 1$ (scavenger receptor B1; regulates cholesterol uptake) mRNA expression was significantly down-regulated $(p<0.01)$ in all PFOA exposure groups, noticeably following $200 \mu \mathrm{M}$ PFOA which declined to $0.16 \pm 0.04$ folds compared to controls. SREBP2 (sterol regulatory element-binding protein 2; controls cholesterol homeostasis) result is consistent with the $S R-B 1$ observation; SREBP2 expression significantly declined (0.74- to 0.51 -fold compared to controls, $p<0.01$; Figure 2) with various concentrations of PFOA exposure in MLTC-1 cells. 


\subsection{PFOA alters fatty acids transport into mitochondria}

Considering PFOA's structural similarity to endogenous fatty acids, the potential interactive-relationship of PFOA and fatty acids in mitochondria were investigated by investigating PFOA subcellular mitochondrial distribution (Fig. 3A) and then determining candidate gene expression coding for enzymes involved in fatty acids mitochondrial transport (Fig. 3B and C). Our results confirm that PFOA can transport into subcellular mitochondria via PFOA accumulation. Figure $3 \mathrm{~A}$ shows the subcellular accumulation of PFOA in cytoplasm and mitochondria. Following PFOA exposure, it was detected in both cytoplasmic and mitochondrial fractions. Following $100 \mu \mathrm{M}$ PFOA exposure, the medium concentration of PFOA was $41.3 \pm 1.1 \mathrm{ppm}$, the PFOA content was $129.0 \pm 3.8 \mu \mathrm{g} / \mathrm{g} \operatorname{Pr}(\mu \mathrm{g}$ PFOA/g protein) in the cytoplasm and $6.4 \pm 0.3 \mu \mathrm{g} / \mathrm{g}$ Pr in mitochondria, respectively. Meanwhile, the control group PFOA content was $0.09 \pm 0.01 \mathrm{ppb}, 1.0 \pm 0.1 \mu \mathrm{g} / \mathrm{g}$ Pr, and $0.7 \pm 0.1 \mu \mathrm{g} / \mathrm{g}$ Pr in medium, cytoplasm and mitochondria, respectively.

Meanwhile, CPTii (carnitine-palmitoyltransferase ii) responsible for connecting carnitine to long-chain fatty acids, which facilitates them crossing the outer mitochondrial membrane, was significantly down-regulated $(p<0.05) \quad$ (Fig. 3B, 3C). CACT (carnitine-acylcarnitine translocase) is a carnitine carrier protein, a component of the mitochondrial inner membrane and transfers fatty acylcarnitines into the mitochondria, was not significantly altered following different PFOA exposure levels (Fig. 3B, 3C). However, CPTii (carnitine-palmitoyltransferase ii), coding for the inner mitochondrial membrane protein that converts acylcarnitine to acyl-CoA for further fatty acid metabolism, was significantly $(p<0.01)$ induced following $100 \mu \mathrm{M}$ (1.34-fold) or $200 \mu \mathrm{M}$ (1.69-fold) PFOA 
(Fig. 3B). Mitochondrial matrix enzyme CRAT (carnitine acetyltransferase), that catalyses the

237

238 inter-conversion of acetyl-CoA and acetylcarnitine, was also significantly $(p<0.01)$ induced (1.71-fold) following $200 \mu \mathrm{M}$ PFOA exposure (Fig. 3B, 3C).

\subsection{PFOA disturbs cholesterol synthesis transcriptional profile and secretion}

Cholesterol and steroid hormone biosynthesis is regulated by steroidogenic genes. The effects of PFOA exposure on expression of genes involved in cholesterol biosynthesis or steroidogenesis in MLTC-1 were determined (Fig. 4 and Table 2). Quantitative real-time RT-PCR assays results show that cholesterol biosynthesis pathway-related genes expression were down-regulated $(0.29-0.87$-fold $)$ significantly $(p<0.01)$ in the $200 \mu \mathrm{M}$ PFOA-treated group compared to vehicle control. Interestingly, $50 \mu \mathrm{M}$ PFOA exposure significantly ( $p$ $<0.05)$ induced $M V K$ (1.52-fold), PMVK (1.52-fold), $M V D$ (1.23-fold), FOPS (1.35-fold) and CYP5 (1.74-fold) gene expression (Fig. 4, Table 2). Especially, HMGCR, an enzyme involved in mevalonate synthesis and is rate-limiting in the cholesterol synthesis pathway, was significantly down-regulated in a dose-related manner after PFOA exposure: 0.85-, 0.82-, and 0.36-fold for 50, 100 and $200 \mu \mathrm{M}$ PFOA-treatment groups, respectively (Fig. 4, Table 2).

Moreover, the effects of PFOA on cholesterol levels in MLTC-1 cells are shown as Figure 4C. Cholesterol was markedly decreased $(p<0.05)$ to $0.83-, 0.87$ - and 0.85 -fold of control following exposures of 50, 100 and $200 \mu \mathrm{M}$ PFOA, respectively.

3.5. Effects of PFOA on steroidogenesis pathway gene expression and steroid hormone secretion

The expression of genes involved in steroidogenesis were significantly $(p<0.01)$ decreased (0.37-0.71-fold) in the $200 \mu \mathrm{M}$ PFOA-treatment groups compared to the vehicle 
controls (Fig. 5A, 5B). The StAR gene, which is responsible for cholesterol transport to the inner mitochondrial membrane, was also significantly reduced $(p<0.01)$ to $0.80-, 0.65$ - and 0.37 -fold of the controls in the 50, 100 and $200 \mu \mathrm{M}$ PFOA-treated groups, respectively (Fig. 5A, 5B). $3 \beta-H S D$ gene, responsible for converting pregnenolone to progesterone, was markedly reduced $(p<0.01)$ to $0.73-, 0.80$ - and 071 -fold of the control in 50,100 and $200 \mu \mathrm{M}$ PFOA-treated groups, respectively (Fig. 5A, 5B). Similarly, CYP17 $\alpha$, which plays a significant role in steroid hormone synthesis, was also markedly reduced $(p<0.01)$ to 0.63 -fold of the controls in the $200 \mu \mathrm{M}$ PFOA-treated group (Fig. 5A, 5B). Interestingly, no significant differences between the PFOA treatment groups and controls are observed for P450SCC (catalyses cholesterol side-chain cleavage to pregnenolone) and $17 \beta-H S D$ (catalyses androstenedione to testosterone) mRNA expression (Fig. 5A, 5B).

The levels of $17-\mathrm{OH}$ progesterone following $50 \mu \mathrm{M}$ PFOA were above control levels, but no statistical difference was found. For the $100 \mu \mathrm{M}$ PFOA groups, progesterone levels were significantly increased $(p<0.01)$ to 1.31 -fold of the control, whereas at $200 \mu \mathrm{M}$, progesterone were significantly reduced $(p<0.01)$ to 0.53 -fold of control (Fig. 5 C). Similar to 17-OH progesterone, PFOA exposure induced biphasic effects on testosterone production in MLTC-1 cells. PFOA effects at medium dose $(100 \mu \mathrm{M})$ have significantly stimulatory effects $(p<0.01)$ on testosterone production, i.e., 1.84-fold compared to controls, while significantly inhibitory $(p<0.01)$ effects at higher exposures are noted, i.e., 0.50 -fold at $200 \mu \mathrm{M}$ compared to controls (Fig. 5D). 


\section{Discussion}

In the present study, we evaluated the mode of toxicity and steroidogenesis in mouse

Leydig MLTC-1 cells following PFOA exposure to understand toxicological effects in the mouse testis and effects on steroid production. We demonstrate that PFOA has the ability to disrupt fatty acids transport, maybe due to the structural similarity of PFOA and endogenous fatty acids, inhibition of exogenous cholesterol uptake and endogenous cholesterol de novo production via reduced transport and synthesis metabolism pathway genes expression respectively, interruption of sex hormones secretion by altering cholesterol mitochondrial transport and impacting steroidogenic enzyme activity in MLTC-1 cells. PFOA has a non-monotonic effect on testosterone and $17-\mathrm{OH}$ progesterone production with different levels of exposure.

Multiple receptors are involved in the metabolic response to PFOA exposure in rodent liver cells. PPAR $\alpha$ activation, involved in the regulation fatty acid $\beta$-oxidation, and Acoxl (acyl CoA oxidase) is the down-stream target genes [27]. PPAR $\alpha$ activation has been study, PPAR $\alpha$ receptor and Acoxl (data not shown) gene expression are not altered following any exposure of PFOA in Leydig cells. The results suggest that PPAR $\alpha$ receptor in MLTC-1

Leydig cells is less sensitive to PFOA exposure compared to previous liver cells. PXR is the molecular target for a wide range of endogenous and xenobiotic compounds. It is responsible for regulation of lipid metabolism and cholesterol homeostasis by mediating genes for cholesterol uptake $(S R-B 1)$ and efflux $(A B C A 1)$ [27, 29]. Our results reveal distinct patterns for the SR-B1 receptor and PXR gene expression after PFOA treatment in MLTC-1 cells. 
$P X R$ and $S R-B I$ were sensitive to PFOA, which is noticeable, in the $200 \mu \mathrm{M}$ PFOA treatment group and the changes were 2.78- and 0.16-fold for both $P X R$ and $S R-B 1$ compared to controls, respectively. We infer that PFOA disrupts cytoplasmic cholesterol transport via inhibiting SR-B1 uptake function. LH via binding to its receptor (LHR) then controls steroidogenesis. It is noteworthy that the present findings provide novel evidence that PFOA plays a dual role in regulating LHR function in MLTC-1 cells, exhibiting induction at lower exposures $(100 \mu \mathrm{M})$ PFOA and inhibition at higher levels $(200 \mu \mathrm{M})$. Our results are also in agreement with previously reported findings, which also show that acute triiodothyronine exposure stimulates LHR expression, whereas chronic exposure attenuates LHR expression [30]. A possible mechanism may be related to the fact that high LHR levels sensitize testicular cells to LH and facilitate steroidogenesis, whereas, lower LHR levels differ in their effect, and maintenance of normal testosterone secretion requires additional LH secretion [30]. Our testosterone and progesterone results agree with this, and correlate with LHR expression. Hence, it cannot be ignored that PFOA has possible effects on sex hormones biosynthesis via LHR regulation, although the mechanism requires further exploration.

PFCs have structural similarity with endogenous fatty acids, which can alter lipid profiles in liver via induction of hepatic fatty acids metabolism. The gene expression profile in PFOA-exposed rat liver also shows those largest categories of induced genes, which are involved in transport and metabolism of lipids, particularly fatty acids [31]. Our previous work also revealed that PFOA can alter the transport of long-chain fatty acids from the cytosol to mitochondrial matrix via carnitine shuttle [32]. Genes coding for enzymes responsible for unsaturated fatty acids transport have been altered by PFOA in MLTC-1 cells 
(Fig. 3). According to our observation, it is shown that PFOA can inhibit mitochondrial outer membrane fatty acid import-related gene (CPTii), while inducing mitochondrial matrix fatty acid retransformation and oxidation metabolism products export-related gene (CPTii, CRAT) expression. Our results are consistent with a previous study that showed that PFOA induced CPTii and CRAT expression in human, rat and mouse liver cells [31-33]. Because of the structural resemblance of PFOA and endogenous fatty acids, PFOA can be taken up in the in-vitro cell model [34]. Kudo and co-authors imply that both PFOA and fatty acids can transfer into mitochondria, but PFOA is unable to metabolize via $\beta$-oxidation [35]. In agreement, we find that PFOA is transported into MLTC-1 cell cytoplasm and mitochondria. We speculate that MLTC-1 cell reduces PFOA uptake by lowering CPTii expression, while facilitating PFOA elimination by increase CPTii and CRAT expression, which leads to disturbed fatty acids transport; further research is necessary to demonstrate this.

Cholesterol is a main substrate for testosterone biosynthesis. Leydig cells can synthesise cholesterol in endoplasmic reticulum and use several potential sources of cholesterol for steroidogenesis in mitochondria [36]. Previous studies suggest that PFOA can disrupt cholesterol content by altering cholesterol transport and biosynthesis routes [9, 31, 32]. Our results show that PFOA significantly weakens the cholesterol content in MLTC-1 cells. The PXR and SR-B1 nuclear receptor as well as SREBP transcription factors responses associated with cholesterol uptake are been proposed in the MTC-1 cells with PFOA exposure. In order to further investigate the effects of PFOA on the cholesterol biosynthesis pathway in MLTC-1 cells, the expression of a series of important genes in this pathway were determined by quantitative real-time RT PCR. The general down-regulation gene 
expression profiles are in agreement with the cells' cholesterol metabolism content. Specifically, HMGCR is an enzyme involved in mevalonate synthesis and is a rate limiting enzyme in cholesterol synthesis pathway. It was down-regulated by PFOA in rat liver with resulting decreased cholesterol content, while up-regulated in human liver cells resulting in increased cholesterol content $[31,32]$. These inconsistent effects may result from different species and experimental models, which have unique metabolic mechanisms. Meanwhile, acyl-CoA is an important raw material for cholesterol biosynthesis, which is altered via fatty acids transport [32]. This study is consistent with previous MLTC-1 cells results showing that PFOA can inhibit cholesterol biosynthesis in vitro [9]. Herein, PFOA may disrupt cholesterol by both exogenous cholesterol uptake and endogenous cholesterol biosynthesis.

Regarding male reproductive function, the level of testosterone in MLTC-1 cells is significantly stimulated to 1.84 -fold of the control at lower PFOA concentrations $(100 \mu \mathrm{M})$ and inhibited to 0.50 -fold of the control at higher treatment concentrations $(200 \mu \mathrm{M})$. We

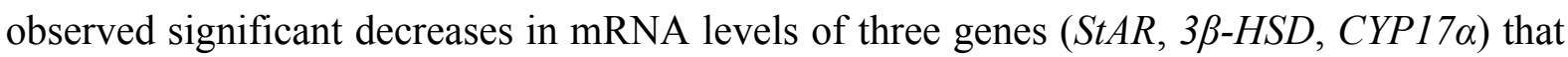
play pivotal roles in testosterone production in MLTC-1 cells exposed by PFOA. StAR is responsible for carrying cholesterol into the inner mitochondrial membrane from the outer mitochondrial membrane, which subsequently converts into pregnenolone by P450SCC in the inner mitochondrial membrane and finally into progesterone via $3 \beta$-HSD catalysis (Fig. 5B). Previous studies have shown that PFCs inhibit the expression of several key enzymes, including StAR, 3 $\beta$-HSD and CYP17 $\alpha[9,37,38]$. However, in the present study, low exposure concentrations of PFOA stimulated testosterone production and high concentrations of PFOA inhibited testosterone production, though the process occurred without any 
alteration of MLTC-1 cell viability. This can be explained by the fact that many environmental endocrine disruptor chemicals are reported to exhibit the ability to induce $\mathrm{U}$ and/or invert U dose-response trends, which results into low-dose stimulation responses [39]. Similar studies have shown that exposures to low or high levels of phthalates or prolactin have biphasic effects on testosterone production in MLTC-1 cells [40-42]. Alteration of cholesterol transport and steroidogenic enzymes in MLTC-1 cells may be involved in the biphasic effects of PFOA on androgen production. Our findings agree with the hypothesis that low-dose stimulation corresponds to a negative feedback compensation mechanism that counterbalances the endocrine disrupting chemicals-induced inhibition of gene expression of the steroidogenic enzymes [43-44]. In conclusion, our results suggest that PFOA disrupts cholesterol precursor fatty acid transport into mitochondria and then alters cholesterol synthesis. Meanwhile, PFOA-regulated nuclear (membrane) receptor response and steroidogenesis result in disruption of sex hormones secretion. In particular, PFOA has a biphasic effect on testosterone and progesterone production.

\section{Conflict of interest statement}

The authors declare that there are no conflicts of interest.

\section{Acknowledgments}

This work is financially supported by the National Nature Science Foundation of China (NSFC-21677142, 21307126, 21777157) and the related NSFC-Royal SocietyInternational Exchange Programme 2013 (21311130119), the Nature Science Foundation of Fujian Province (2017J01027) and the Knowledge Innovation Program of the Chinese Academy of Sciences (IUEQN201506, KLUEH-201802). 


\section{References}

[1] J. P. Giesy, and K. Kannan. Perfluorochemical surfactants in the environment. Environ. Sci. Technol. 36, (2002)146-152.

[2] E.T. Chang, H.O. Adami, P. Boffetta, P. Cole, T.B. Starr, J.S. Mandel. A critical review of perfluorooctanoate and perfluorooctanesulfonate exposure and cancer risk inhumans. Crit. Rev. Toxicol. 44 (Suppl. 1) (2014) 1-81.

[3] C. Lau. Perfluoroalkyl acids: recent research highlights. Reprod. Toxicol. 33 (4) (2012) 405-409.

[4] G.W. Olsen, J.M. Burris, D.J. Ehresman, J.W. Froehlich, A.M. Seacat, J.L. Butenhoff, L.R. Zobel. Half-life of serum elimination of perfluorooctanesulfonate, perfluorohexanesulfonate, and perfluorooctanoate in retired fluorochemical production workers. Environ. Health Perspect. 115 (9) (2007) 1298-1305.

[5] L. B. Biegel, M. E. Hurtt, S. R. Frame, J. C. O’Connor, J. C. Cook. Mechanisms of extrahepatic tumor induction by peroxisome proliferators in male CD rats. Toxicol. Sci. 60 (1) (2001) 44-55.

[6] E. Corsini, A. Avogadro, V. Galbiati, M. dell'Agli, M. Marinovich, C.L. Galli, D.R. Germolec. In vitro evaluation of the immunotoxic potential of perfluorinated compounds (PFCs). Toxicol. Appl. Pharmacol. 250 (2) (2010) 108-116.

[7] C. Lau, K. Anitole, C. Hodes, D. Lai, A. Pfahles-Hutchens, J. Seed. Perfluoroalkyl acids: a review of monitoring and toxicological findings. Toxicol. Sci. 99 (2) (2007) 366-394.

[8] K. Steenland, T. Fletcher, D. A. Savitz. Epidemiologic evidence on the health effects of perfluorooctanoic acid (PFOA). Environ. Health Perspect. 118 (8) (2010)1100-1108.

[9] H. Zhang, Y. Lu, B. Luo, S. Yan, X. Guo, J. Dai. Proteomic analysis of mouse testis reveals perfluorooctanoic acid-induced reproductive dysfunction via direct disturbance of testicular steroidogenic machinery. J. Proteome Res. 13 (7) (2014) 3370-3385.

[10]B. Zhao, Y. Chu, D. O. Hardy, X. K. Li, R. S. Ge. Inhibition of 3beta- and 17beta-hydroxysteroid dehydrogenase activities in rat Leydig cells by perfluorooctane acid. J. Steroid Biochem. Mol. Biol. 118 (1-2) (2010) 13-17.

[11]A. S. Mortensen, R. J. Letcher, M. V. Cangialosi, S. Chu, A. Arukwe. Tissue 
bioaccumulation patterns, xenobiotic biotransformation and steroid hormone levels in Atlantic salmon (Salmo salar) fed a diet containing perfluoroactane sulfonic or perfluorooctane carboxylic acids. Chemosphere 83 (8) (2011) 1035-1044.

[12]Y. Wei, J. Dai, M. Liu, J. Wang, M. Xu, J. Zha, Z. Wang. Estrogen-like properties of perfluorooctanoic acid as revealed by expressing hepatic estrogen-responsive genes in rare minnows (Gobiocypris rarus). Environ. Toxicol. Chem. 26 (11) (2007) 2440-2447.

[13]G. Du, H. Huang, J. Hu, Y. Qin, D. Wu, L. Song, Y. Xia, X. Wang. Endocrine-related effects of perfluorooctanoic acid (PFOA) in zebrafish, H295R steroidogenesis and receptor reporter gene assays. Chemosphere 91(8) (2013) 1099-1106.

[14]U. N. Joensen, B. Veyrand, J. P. Antignac, M. Blomberg Jensen, J. H. Petersen, P. Marchand, N. E. Skakkebaek, A. M. Andersson, B. Le Bizec, N. Jorgensen. PFOS (perfluorooctanesulfonate) in serum is negatively associated with testosterone levels, but not with semen quality, in healthy men. Hum. Reprod. 28 (3) (2013) 599-608.

[15]M.J. Lopez-Espinosa, T. Fletcher, B. Armstrong, B. Genser, K. Dhatariya, D. Mondal, A. Ducatman, G. Leonardi. Association of perfluorooctanoic acid (PFOA) and perfluorooctane sulfonate (PFOS) with age of puberty among children living near a chemical plant. Environ. Sci. Technol. 45 (19) (2011) 8160-8166.

[16]Y. Zhou, L.W. Hu, Z.M. Qian, J.J. Chang, C. King, G. Paul, S. Lin, P.C. Chen, Y.L. Lee, G.H. Dong. Association of perfluoroalkyl substances exposure with reproductive hormone levels in adolescents: By sex status. Environ. Int. 94 (2016) 189-95.

[17]M. Maisonet, A.M. Calafat, M. Marcus, J J.J. aakkola, H. Lashen. Prenatal exposure to perfluoroalkyl acids and serum testosterone concentrations at 15 years of age in female ALSPAC study participants. Environ. Health Perspect. 123 (2) (2015) 1325-1330.

[18]G. W. Olsen, F. D. Gilliland, M. M. Burlew, J. M. Burris, J. S. Mandel, J. H. Mandel. An epidemiologic investigation of reproductive hormones in men with occupational exposure to perfluorooctanoic acid. J. Occup. Environ. Med. 40 (7) (1998) 614-622.

[19]A.C. Behr, D. Lichtenstein, A. Braeuning, A. Lampen, T. Buhrke. Perfluoroalkylated substances (PFAS) affect neither estrogen and androgen receptor activity nor steroidogenesis in human cells in vitro. Toxicol Lett. 291 (2018) 51-60.

[20]A. Vested, C. H. Ramlau-Hansen, S. F. Olsen, J. P. Bonde, S. L. Kristensen, T. I. 
Halldorsson, G. Becher, L. S. Haug, E. H. Ernst, G. Toft. Associations of in utero exposure to perfluorinated alkyl acids with human semen quality and reproductive hormones in adult men. Environ. Health Perspect. 121 (4) (2013) 453-458.

[21]U. N. Joensen, R. Bossi, H. Leffers, A. A. Jensen, N. E. Skakkebaek, N. Jørgensen. 2009. Do perfluoroalkyl compounds impair human semen quality? Environ. Health Perspect. 117 (6) (2009) 923-927.

[22]J. H. Raymer, L. C. Michael, W. B. Studabaker, G. W. Olsen, C. S. Sloan, T. Wilcosky, D. K. Walmer. 2012. Concentrations of perfluorooctane sulfonate (PFOS) andperfluorooctanoate (PFOA) and their associations with human semen quality measurements. Reprod. Toxicol. 33 (4) (2012) 419-427.

[23]M. Bochud, J. Jenny-Burri, M. Pruijm. Urinary Cadmium Excretion Is Associated With Increased Synthesis of Cortico- and Sex Steroids in a Population Study. J Clin Endocrinol Metab. 103 (2) (2018) 748-758.

[24]K. Svechnikov, I. Savchuk, M.L. Morvan, J.P. Antignac , B. Le Bizec, O. Söder. Phthalates Exert Multiple Effects on Leydig Cell Steroidogenesis. Hormone Research Paediatrics 86(4) (2016) 253-263.

[25]L. Liu, J. She, X. Zhang, J. Zhang, M. Tian, Q. Huang, H. Shen. Online background cleanup followed by high-performance liquid chromatography with tandem mass spectrometry for the analysis of perfluorinated compounds in human blood. J. Sep. Sci. 38 (2) (2015) 247-253.

[26]G. W. Olsen, M. E. Ellefson, D. C. Mair, T. R. Church, C. L. Goldberg, R. M. Herron, L.R. Zobel. Analysis of a homologous series of perfluorocarboxylates from American Red Cross adult blood donors, 2000-2001 and 2006. Environ. Sci. Technol. 45 (19) (2011) 8022-8029.

[27]J. A. Bjork, J. L. Butenhoff, K. B. Wallace. 2011. Multiplicity of nuclear receptor activation by PFOA and PFOS in primary human and rodent hepatocytes. Toxicology $288(1-3)(2011) 8-17$.

[28]S. Yan, J. Wang, J. Dai. Activation of sterol regulatory element-binding proteins in mice exposed to perfluorooctanoic acid for 28 days. Arch Toxicol. (89) (2015) 1569-78. 
[29]M. Sporstøl, G. Tapia, L. Malerød, S. A. Mousavi, T. Berg. 2005. Pregnane X receptor-agonists down-regulate hepatic ATP-binding cassette transporter A1 and scavenger receptor class B type I. Biochem. Biophys. Res. Commun. 331 (2005) 1533-1541.

[30]P. R. Manna, J. Kero, M. Tena-Sempere, P. Pakarinen, D.M. Stocco, I. T. Huhtaniemi. Assessment of mechanisms of thyroid hormone action in mouse Leydig cells: regulation of the steroidogenic acute regulatory protein, steroidogenesis, and luteinizing hormone receptor function. Endocrinology 142 (1) (2001) 319-331.

[31]K. S. Guruge, L. W. Yeung, N. Yamanaka, S. Miyazaki, P. K. Lam, J. P. Giesy, P. D. Jones, N. Yamashita. Gene expression profiles in rat liver treated with perfluorooctanoic acid (PFOA). Toxicol. Sci. 89 (1) (2006) 93-107.

[32]S. Peng, L. Yan, J. Zhang, Z. Wang, M. Tian, H. Shen. An integrated metabonomics and transcriptomics approach to understanding metabolic pathway disturbance induced by perfluorooctanoic acid. J. Pharm. Biomed. Anal. 86 (2013) 56-64.

[33]M. B. Rosen, J. R. Thibodeaux, C.R. Wood, R. D. Zehr, J. E. Schmid, C. Lau. Gene expression profiling in the lung and liver of PFOA-exposed mouse fetuses. Toxicology 239 (1-2) (2007)15-33.

[34]E. Gorrochategui, E. Pérez-Albaladejo, J. Casas, S. Lacorte, C. Porte. Perfluorinated chemicals: differential toxicity, inhibition of aromatase activity and alteration of cellular lipids in human placental cells. Toxicol. Appl. Pharmacol. 277 (2) (2014) 124-130.

[35]N. Kudo, E. Suzuki, M. Katakura, K. Ohmori, R. Noshiro, Y. Kawashima. Comparison of the elimination between perfluorinated fatty acids with different carbon chain length in rats. Chem. Biol. Interact. 134 (2) (2001) 203-216.

[36]N. S. Panesar, K. W. Chan, C. S. Ho. 2003. Mouse Leydig tumor cells produce C-19 steroids, including testosterone. Steroids 68 (3) (2003) 245-251.

[37]Z. Shi, H. Zhang, Y. Liu, M. Xu, J. Dai. 2007. Alterations in Gene Expression and Testosterone Synthesis in theTestes of Male Rats Exposed to Perfluorododecanoic Acid. Toxicol. Sci. 98 (1) (2007) 206-215.

[38]Z. Shi, L. Ding, H. Zhang, Y. Feng, M. Xu, J. Dai. 2009. Chronic exposure to perfluorododecanoic acid disrupts testicular steroidogenesis and the expression of related 
genes in male rats. Toxicol. Lett. 188 (2009) 192-200

[39]A. Kinoshita, H. Wanibuchi, K. Morimura, M. Wei, J. Shen, S. Imaoka, Y. Funae, S. Fukushima. Phenobarbital at low dose exerts hormesis in rat hepatocarcinogenesis by reducing oxidative DNA damage, altering cell proliferation, apoptosis and gene expression. Carcinogenesis 24 (8) (2003) 1389-1399.

[40]X. Chen, Q. H. Zhou, L. Leng, X. Chen, Z. R. Sun, N. J. Tang. Effects of di (n-butyl) and monobutyl phthalate on steroidogenesis pathways in the murine Leydig tumor cell line MLTC-1. Environ. Toxicol. Pharmacol. 36 (2) (2013) 332-338.

[41]M. Tian, L. Liu, H. Wang, X. Wang, L. F. Martin, J. Zhang, Q. Huang, H. Shen, Phthalates induce androgenic effects at exposure levels that can be environmentally relevant in humans. Environ. Sci. Technol. Lett. 5 (5) (2018) 232-236.

[42]P. R. Manna, T. El-Hefnawy, J. Kero, I.T. Huhtaniemi. 2001. Biphasic action of prolactin in the regulation of murine Leydig tumor cell functions. Endocrinology 142 (1) (2001) 308-318.

[43]M. Oudir, H. Chader, B. Bouzid, K. Bendisari, B. Latreche, S. Boudalia, M. Iguer-Ouada. Male rat exposure to low dose of di (2-ethylhexyl) phthalate during pre pubertal, pubertal and post-pubertal periods impact on sperm count, gonad histology and testosterone secretion. Reprod Toxicol. 75 (2018) 33-39.

[44]E.P. Murono, R.C. Derk, J.H. de León. Biphasic effects of octylphenol on testosterone biosynthesis by cultured Leydig cells from neonatal rats. Reprod Toxicol. 13(6) (1999) 451-62. 
Figure 1. The viability of MLTC-1 cells exposed to various concentrations of PFOA (0-300

$\mu \mathrm{M})$ for $48 \mathrm{~h}$. The values are expressed as the means ( \pm SEM) of survival ( $\%$ of control cells).

Data were analysed by one-way ANOVA with Tukey's multiple comparisons test. Asterisks

536

537

538 above columns indicate a significant difference in comparison to the control, ${ }^{*} p \leq 0.05,{ }^{* *} p$ $\leq 0.01$.

Figure 2. Effects of PFOA on the mRNA expression of receptor genes. MLTC-1 cells were exposed to different doses of PFOA $(0,50,100$ or $200 \mu \mathrm{M})$ for $48 \mathrm{~h}$. The relative mRNA expression of PPAR $, A R, P X R, L H R$ and $S R-B 1$ gene were measured by quantitative real-time RT PCR. The experiments were repeated four times in duplicate. Data were analysed by one-way ANOVA with Tukey's multiple comparisons test. Asterisks above columns indicate a significant difference in comparison to the control, $* p \leq 0.05, * * p \leq 0.01$.

Figure 3. Effects of PFOA on the subcellular accumulation (A), fatty acids mitochondria transport genes expression (B) in MLTC-1 cells and schematic diagram of fatty acids mitochondrial transport (C).

Mean \pm SEM is derived from four independent experiments. Fraction isolated: cytoplasm and mitochondria. 
553 Figure 4. PFOA affect cholesterol biosynthetic pathways gene expression and content in 554 MLTC-1 cells. Heat map displays fold-changes of PFOA exposure on cholesterol 555 biosynthetic pathways gene expression profiles (A), effects of PFOA on the cholesterol 556 biosynthesis pathway gene expression in MLTC-1 cells in $200 \mu \mathrm{M}$ treatment (B), and effects 557 of PFOA exposure on cholesterol level in MLTC-1 cells (C).

558 Colour scales range from bright red to bright green corresponding to up- or down-regulation of gene expression, respectively. The experiments were repeated four times in duplicate. Data were analysed by one-way ANOVA with Tukey's multiple comparisons test. Asterisks above columns indicate a significant difference in comparison to the control, ${ }^{*} p \leq 0.05,{ }^{* *} p \leq 0.01$.

562

Figure 5. PFOA affect steroid hormone biosynthetic pathways in MLTC-1 cells, 564 steroidogenesis gene expression (A), steroidogenesis gene pathway (B), 17-OH progesterone secretion (C), and testosterone secretion (D).

566 The experiments were repeated four times in duplicate. Data were analysed by one-way ANOVA with Tukey's multiple comparisons test. Asterisks above columns indicate a significant difference in comparison to the control, ${ }^{*} p \leq 0.05,{ }^{* *} p \leq 0.01$. 
Table 1. Sequence of primers used for quantitative real-time PCR.

\begin{tabular}{|c|c|c|c|}
\hline Gene & Accession number & Primer sequence $\left(5^{\circ}-3^{\prime}\right)$ & Product size (bp) \\
\hline$G A P D H$ & NM_001289746.1 & $\begin{array}{l}\text { F: GTATTGGGCGCCTGGTCACC } \\
\text { R: CGCTCCTGGAAGATGGTGATGG }\end{array}$ & 202 \\
\hline CPTii & XM_006531658.3 & $\begin{array}{l}\text { F: AACAACCGTAGGCTCCACCGT } \\
\text { R: ATTCAAAAGACTTCGGGGGAC }\end{array}$ & 99 \\
\hline$C A C T$ & NM_020520.4 & $\begin{array}{l}\text { F: CAGATTCAGGCTTCTTCAGGG } \\
\text { R: ACTGGCAGGAACATCTCGCAT }\end{array}$ & 135 \\
\hline CPTii & NM_009949.2 & $\begin{array}{l}\text { F: TGGCTTTCCTGCGACAGTATG } \\
\text { R: GGCGAATAGTCTCTGTGCGGC }\end{array}$ & 93 \\
\hline$C A T$ & XM_006497646.3 & $\begin{array}{l}\text { F: AAGTCAAAGAGACCACCCACG } \\
\text { R: GGAGGTTAGGATGCCAACAGG }\end{array}$ & 177 \\
\hline$P P A R \alpha$ & XM_006520624.3 & $\begin{array}{l}\text { F: GGAGAACAAGAGACGAGGGTG } \\
\text { R: CAGGGACTGAGGAAAAGGGAC }\end{array}$ & 157 \\
\hline$A R$ & NM_013476.4 & $\begin{array}{l}\text { F: CTTTCAAGGGAGGTTACGCCA } \\
\text { R: ACAGAGACAGAGAGGACGGGA }\end{array}$ & 111 \\
\hline$P X R$ & XM_006521848.3 & $\begin{array}{l}\text { F: TGAAAGACAGGGTTCCAATGA } \\
\text { R: GTGTGGCAGAAGAGGGATGAT }\end{array}$ & 119 \\
\hline$L H R$ & XM_006523723.2 & $\begin{array}{l}\text { F: GAGAAGCGAATAACGAGACG } \\
\text { R: AGCCAAATCAACACCCTAAG }\end{array}$ & 178 \\
\hline$S R-B 1$ & XM_017320764.1 & $\begin{array}{l}\text { F: } \text { TTGTTCTACCTCCTCTCTCGC } \\
\text { R: CTGACCCCCCACCTCTACCTT }\end{array}$ & 179 \\
\hline StAR & NM_011485.5 & $\begin{array}{l}\text { F: TGGAAAAGACACGGTCATCA } \\
\text { R: CTCCGGCATCTCCCCAAAAT }\end{array}$ & 154 \\
\hline P450SCC & NM_001346787.1 & $\begin{array}{l}\text { F: CGTGACCAGAAAAGACAACA } \\
\text { R: AGGATGAAGGAGAGGAGAGC }\end{array}$ & 152 \\
\hline $3 \beta-H S D$ & NM_001304800.1 & $\begin{array}{l}\text { F: AGTGATGGAAAAAGGGCAGGT } \\
\text { R: GCAAGTTTGTGAGTGGGTTAG }\end{array}$ & 167 \\
\hline CYP17 & NM_007809.3 & $\begin{array}{l}\text { F: } \text { TGGGCACTGCATCACGATAA } \\
\text { R: GCTCCGAAGGGCAAATAACT }\end{array}$ & 122 \\
\hline $17 \beta-H S D$ & NM_008291.3 & $\begin{array}{l}\text { F: AACGCAACATCAGCAACAGA } \\
\text { R: CAGCCCCACCTCACCCTACC }\end{array}$ & 88 \\
\hline$H M G C S 1$ & NM_001291439.1 & $\begin{array}{l}\text { F: GCTGTCATCAGTAACGGGGAG } \\
\text { R: CCAAGACATCCATTCCTCCAA }\end{array}$ & 99 \\
\hline$H M G C R$ & XM_006517531.1 & $\begin{array}{l}\text { F: ACCAAACCCCGTAACCCAAAG } \\
\text { R: GCCAAAAGGAAGGCTAAACTC }\end{array}$ & 255 \\
\hline$M V K$ & XM_006530185.3 & $\begin{array}{l}\text { F: GAGCAATGGGAAAGTGAGCGT } \\
\text { R: GGAGGTCCCCCATCTTCTTTA }\end{array}$ & 161 \\
\hline$P M V K$ & NM_026784.3 & $\begin{array}{l}\text { F: AGGCTCTTTCCCTTCCAGTTT } \\
\text { R: GTCCTTCCCGGATTTTCTCTT }\end{array}$ & 255 \\
\hline$M V D$ & NM_138656.2 & $\begin{array}{l}\text { F: ACAAGAAGCAGACGGGCAGTA } \\
\text { R: AGGTAGGAGATCGGTGGGAAG }\end{array}$ & 217 \\
\hline IDII & XM_006498513.3 & $\begin{array}{l}\text { F: ATCCACCTTCCTCTGACTCCC } \\
\text { R: AGCCCTACTCCTTCCCACTTC }\end{array}$ & 161 \\
\hline FDPS & NM_001253751.1 & $\begin{array}{l}\text { F: ACAGTGGGCTGGTGTGTAGAA } \\
\text { R: CAGAAGCAGAGCGTCGTTGAT }\end{array}$ & 147 \\
\hline FDFT1 & XM_006518547.3 & $\begin{array}{l}\text { F: GAACTCATAACCAACACCCTA } \\
\text { R: CCTTCCGAATCTTCACTACTC }\end{array}$ & 175 \\
\hline$S Q L E$ & NM_009270.3 & $\begin{array}{l}\text { F: ACAGCCACATTCGCACCCCTC } \\
\text { R: CATTTAAAGCCTGCCTACCCC }\end{array}$ & 107 \\
\hline
\end{tabular}




\begin{tabular}{|c|c|c|c|}
\hline LSS & XM_006513284.3 & $\begin{array}{l}\text { F: CTCCAGAATGAGTTGGGTCGG } \\
\text { R: GCTGTTTGCGCTTTTGGTAAG }\end{array}$ & 143 \\
\hline CYP51A1 & NM_020010.2 & $\begin{array}{ll}\text { F: } & \text { TTTCCGAGAAGCGGTGTGCGA } \\
\text { R: } & \text { ACGGCGAGACGGAACAGGTAG }\end{array}$ & 207 \\
\hline$S C 4 M O L$ & NM_025436.2 & $\begin{array}{ll}\text { F: } & \text { TTTGGCAAGGTGTTTGGGCTG } \\
\text { R: } & \text { CAAGGGATGTGCGTATTCTGC }\end{array}$ & 157 \\
\hline$N S D H L$ & NM_010941.3 & $\begin{array}{l}\text { F: CTGAAGACCTCCCTTACGCCA } \\
\text { R: TTCTTAGGGTCGTTGGCATCC }\end{array}$ & 97 \\
\hline$S C 5 D L$ & XM_006510253.2 & $\begin{array}{l}\text { F: GCTTTTCACCCTGTGGACGGC } \\
\text { R: CTGGGGAACCCGAAAATCACC }\end{array}$ & 153 \\
\hline DHCR7 & XM_006508479.3 & $\begin{array}{l}\text { F: } \text { TTGAAGAAGGGAGGCTTTTTT } \\
\text { R: }\end{array}$ & 191 \\
\hline
\end{tabular}

571 
Table 2 Effect of PFOA on mRNA expression of cholesterol biosynthetic pathways genes in MLTC-1 cells

575

\begin{tabular}{lllll}
\hline & DMSO & $50 \mu \mathrm{M} \mathrm{PFOA}$ & $100 \mu \mathrm{M} \mathrm{PFOA}$ & $200 \mu \mathrm{M} \mathrm{PFOA}$ \\
\hline$H M G C S$ & $1.00 \pm 0.02$ & $0.92 \pm 0.04$ & $0.82 \pm 0.05^{* *}$ & $0.49 \pm 0.07^{* *}$ \\
$H M G C R$ & $1.00 \pm 0.05$ & $0.85 \pm 0.11^{*}$ & $0.82 \pm 0.05^{* *}$ & $0.36 \pm 0.05^{* *}$ \\
$M V K$ & $1.00 \pm 0.04$ & $1.52 \pm 0.14^{* *}$ & $1.27 \pm 0.12^{*}$ & $0.87 \pm 0.07$ \\
PMVK & $1.00 \pm 0.03$ & $1.52 \pm 0.15^{* *}$ & $1.26 \pm 0.09^{*}$ & $0.73 \pm 0.03^{*}$ \\
MVD & $1.00 \pm 0.08$ & $1.23 \pm 0.14^{*}$ & $1.17 \pm 0.11$ & $0.58 \pm 0.07^{* *}$ \\
IDI1 & $1.00 \pm 0.08$ & $0.90 \pm 0.08$ & $0.75 \pm 0.04^{* *}$ & $0.37 \pm 0.05^{* *}$ \\
FDPS & $1.00 \pm 0.10$ & $1.35 \pm 0.09^{* *}$ & $1.09 \pm 0.05$ & $0.43 \pm 0.08^{* *}$ \\
FDFT1 & $1.00 \pm 0.06$ & $0.89 \pm 0.04^{*}$ & $0.84 \pm 0.03^{* *}$ & $0.58 \pm 0.03^{* *}$ \\
SQLE & $1.00 \pm 0.04$ & $0.87 \pm 0.07^{*}$ & $0.80 \pm 0.05^{* *}$ & $0.36 \pm 0.04^{* *}$ \\
LSS & $1.00 \pm 0.05$ & $1.13 \pm 0.08$ & $1.22 \pm 0.11$ & $0.43 \pm 0.08^{* *}$ \\
CYP5 & $1.00 \pm 0.06$ & $1.74 \pm 0.08^{* *}$ & $1.35 \pm 0.17^{*}$ & $0.29 \pm 0.04^{* *}$ \\
SC4MOL & $1.00 \pm 0.03$ & $1.07 \pm 0.07$ & $0.98 \pm 0.06$ & $0.44 \pm 0.08^{* *}$ \\
NSDHLC & $1.00 \pm 0.09$ & $0.97 \pm 0.02$ & $1.09 \pm 0.09$ & $0.53 \pm 0.05^{* *}$ \\
SC5DL & $1.00 \pm 0.07$ & $0.92 \pm 0.08$ & $0.87 \pm 0.02^{*}$ & $0.48 \pm 0.07^{* *}$ \\
DHCR7 & $1.00 \pm 0.08$ & $1.05 \pm 0.02$ & $1.01 \pm 0.06$ & $1.10 \pm 0.02$ \\
\hline
\end{tabular}

Data are represented as mean \pm SEM of four independent experiments that were performed in duplicate. The one-way analysis of variance (ANOVA) with Tukey's multiple comparisons test was applied to estimate for statistical significance between controls versus treatment groups. Asterisks indicate a significant difference relative to control, ${ }^{*} p \leq 0.05,{ }^{* *} p \leq 0.01$ 
$582 \quad$ Figure 1

583

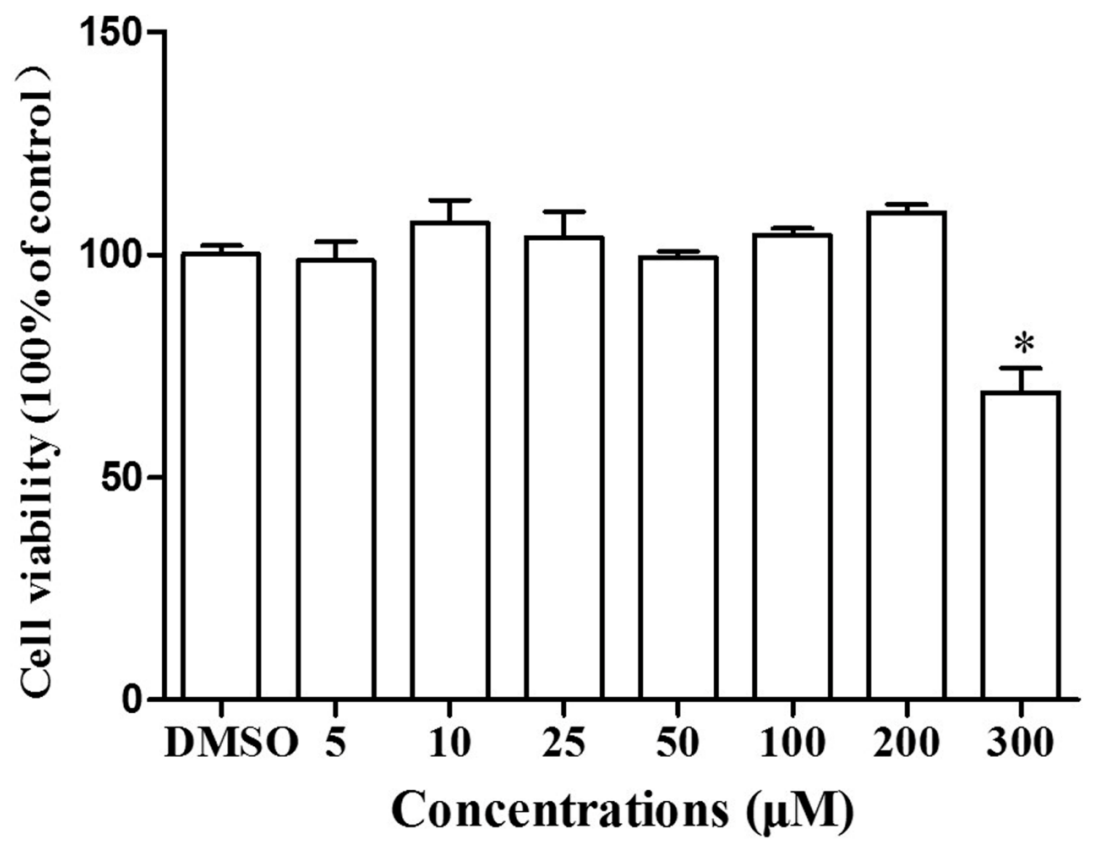


Figure 2

587

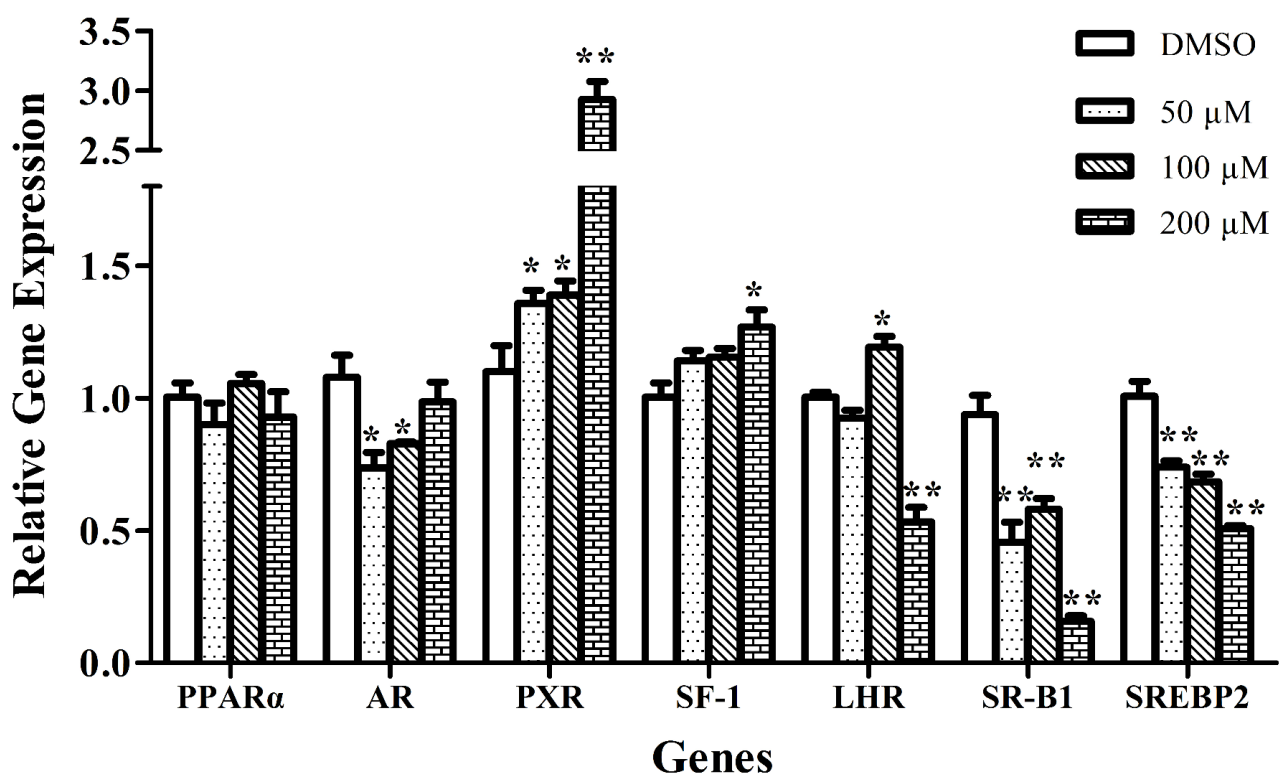


Figure 3

591
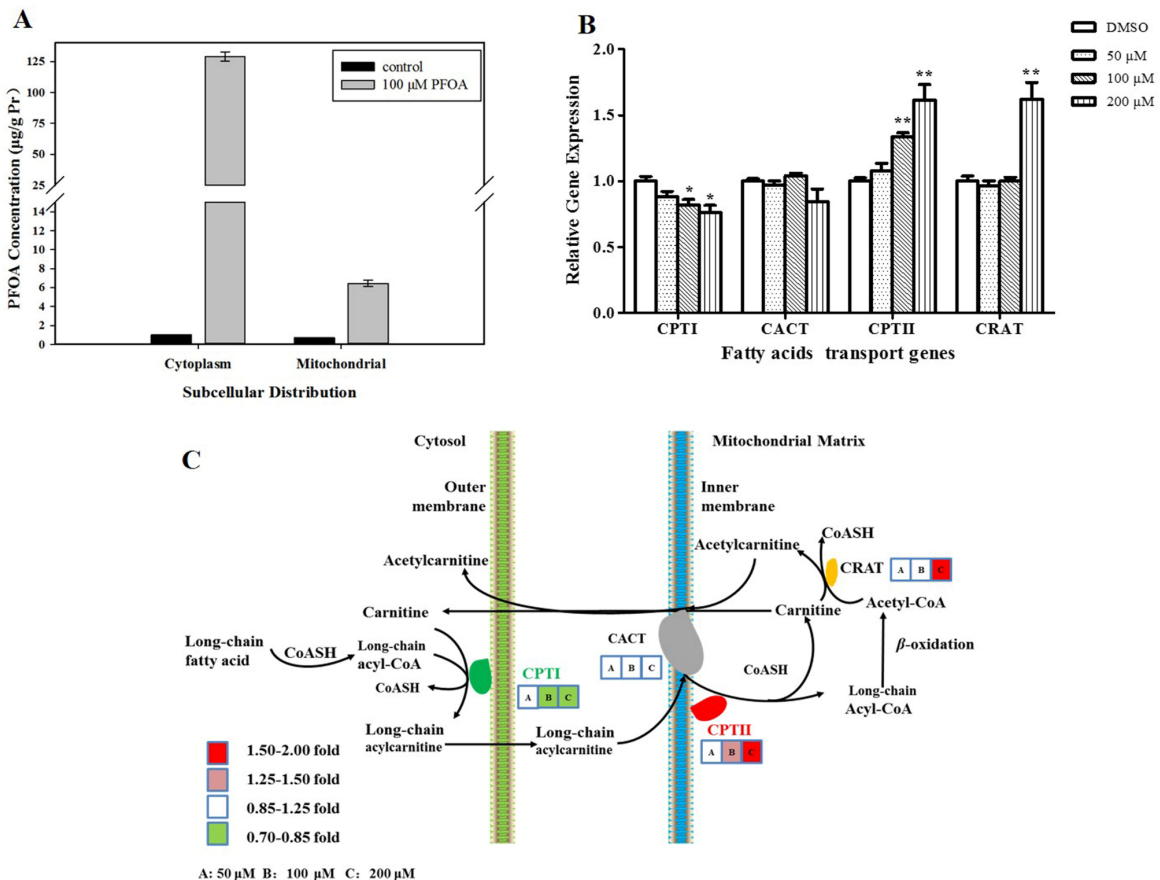
Figure 4

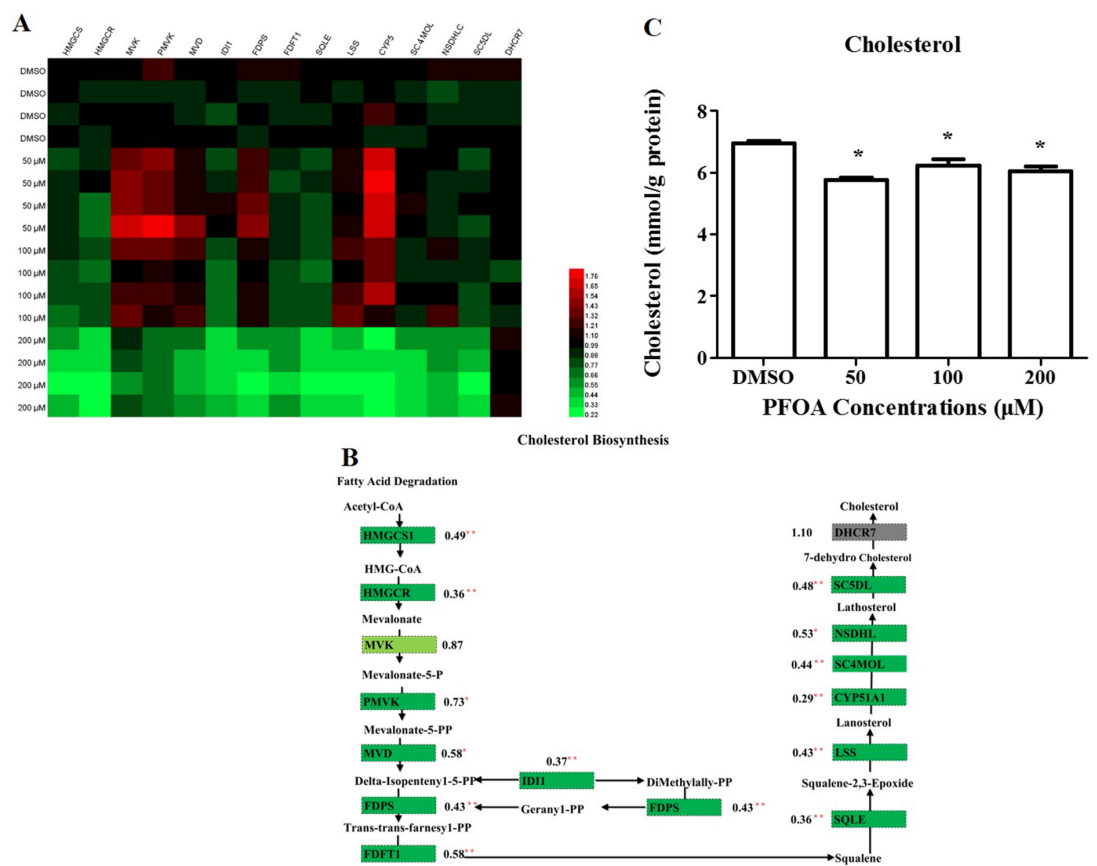



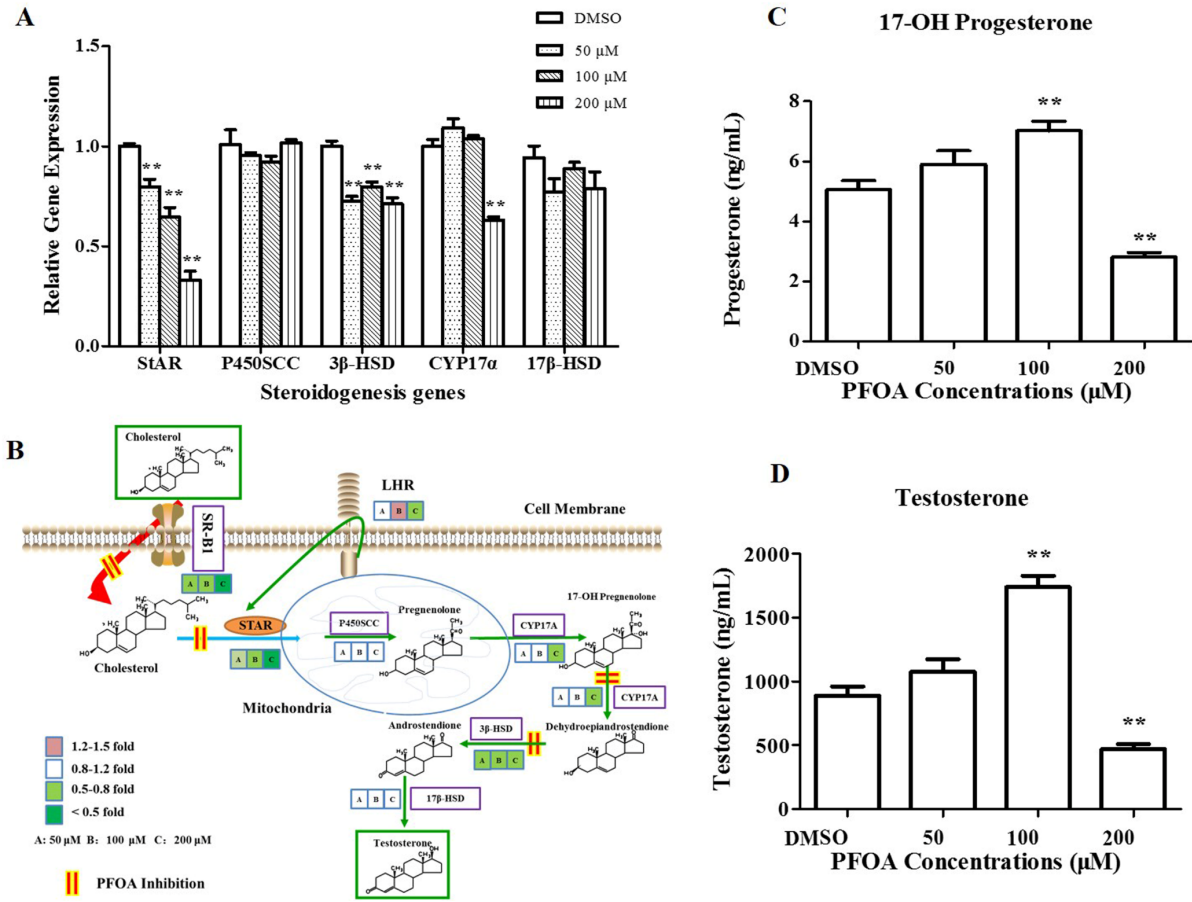